\title{
Variation in the morphosyntax of ONE*
}

\author{
Sjef Barbiers
}

Meertens Instituut, Royal Netherlands Academy of Arts and Sciences, PO Box 94264, 1090 GG Amsterdam, The Netherlands

\section{Introduction}

In English noun ellipsis constructions such as (1a) ONE must appear. This so called ONE insertion is impossible in Standard Dutch (1b), but we find a similar phenomenon in three varieties of Dutch, i.e. some Northern Brabantish dialects (1c), Frisian (1d) and some Groningen dialects (1e). ${ }^{1}$

(1) ONE insertion in N-ellipsis contexts
a. Youare a
strange *(one)
b. Je bent een
rare $\quad(* e ́ e ́ n)$
c. Gè zet unnen
arigen (inne)
d. Do bist in
raren (ien)
e. Doe bis ' $n$
roaren (ain)

The goal of this paper is to answer the following questions:

(i) Is ONE insertion in these varieties of Dutch the same phenomenon as in English?

(ii) Why and under which circumstances does ONE insertion occur?

(iii) How can cross-linguistic variation in ONE insertion be explained?

(iv) What is the locus of variation in ONE insertion, i.e. which level of the grammar is relevant here?

(v) What does ONE insertion tell us about the architecture of nominal constituents?

(vi) What are the morphosyntactic properties of ONE?

I propose the following answers. There are three different types of ONE insertion. ONE insertion in the position of $\mathrm{N}$ is obligatory in English to make the morphosyntactic feature [count] locally visible. ONE insertion in the varieties of Dutch is the result of optional movement of DP or AP to the Spec of numeral ONE. This movement is triggered by a [focus] feature on ONE and it is possible only if ONE fully agrees with the moved constituent.

\footnotetext{
* I thank Hans Bennis, Marcel den Dikken, Magda Devos, Georges de Schutter, Marjo van Koppen, Johan Rooryck, Jan-Wouter Zwart and three anonymous reviewers for helpful comments and suggestions. Parts of this paper were presented at the workshop Dialect Syntax in the West Germania at the University of Freiburg (2001), the ULCL Linguistics Seminar at the University of Leiden (2002), the GLOW Colloquium in Amsterdam (2002; with Martine Greijmans) and the Taal \& Tongval Colloquium at the Royal Academy of Dutch Language and Literature in Gent (2002). A Dutch version of the latter lecture will appear in a special issue on dialect syntax of Taal \& Tongval.

${ }^{1}$ The data of the Dutch varieties were collected by Martine Greijmans (Tilburg University). In NorthernBrabant (in the southern part of the Netherlands) we find ONE insertion in Eindhoven and its surroundings (cf. also De Bont 1962 for Kempenlands). The construction is common in Frisian (cf. Tiersma 1985). In Groningen, the province to the east of Friesland, there are some western dialects that have ONE insertion. I thank Eric Hoekstra, Jarich Hoekstra and Henk Wolf for their help with the Frisian data.
} 
I argue that the syntactic differences between the three types of ONE insertion are the result of the interaction between the morphosyntactic feature specifications of the individual elements of nominal constituents and general conditions on movement. The language varieties discussed in this paper do not differ with respect to the possible base structures of nominal constituents. The proposed analysis of ONE insertion thus provides substantial support for the central minimalist hypothesis (Chomsky 1995) that syntactic variation can be reduced to variation in the lexicon.

As for the properties of ONE, evidence is provided for the novel claim that ONE in Dutch and its varieties does not belong to the paradigm of numerals like TWO, THREE etc. It differs from these numerals in that it has a feature [indefinite] and belongs to the paradigm of indefinite quantifiers such as MANY. This conclusion presumably also holds for the English numeral ONE but not for nominal ONE that we find in English ONE insertion and that only has a feature [count].

\section{ONE insertion: English vs. Standard Dutch}

We start with a comparison of noun ellipsis in English and Standard Dutch. ${ }^{2}$ The core facts for English are given in (2). In English the feature [count] must be locally visible, which means that it must be expressed morphophonologically. ONE insertion occurs with count nouns but not with mass nouns $(2 \mathrm{a}, \mathrm{b})$. When there is a numeral, as in (2c), ONE insertion does not occur, unless an adjective intervenes between the numeral and the normal position of the noun, as in (2d).

\section{(2) Local identification of [count] in English}
a. Talking about cars, I prefer a red $*(o n e)$
b. Talking about wine, I prefer Australian (*one)
c. (Talking about new books,) I have two (*ones)
d. (Talking about books,) I have two new *(ones)

Noun ellipsis in Standard Dutch requires local visibility of the feature [gender] instead of [count]. Gender inflection on the adjective is sufficient to license noun ellipsis, as (3a) shows. When there is no visible gender inflection, noun ellipsis is ungrammatical for most speakers of Standard Dutch (3b). Since numerals in Standard Dutch never have gender inflection, such numerals do not license noun ellipsis (3c). When so called quantitative $e r$ 'there' ${ }^{3}$ is added, noun ellipsis is possible, which suggests that quantitative er has a [gender] feature. The fact that in Standard Dutch er must be absent when there is an inflected adjective supports this conclusion $(3 \mathrm{~d}) .{ }^{4,5}$

\footnotetext{
${ }^{2}$ A more extensive description and analysis can be found in Barbiers (1990). Cf. Kester (1996) for a similar analysis and further references.

${ }^{3}$ Cf. Bennis (1986) and references cited there.

${ }^{4}$ In certain southern varieties of Dutch er may occur in such contexts, but there is reason to belief that the feature make up of $e r$ in such varieties is different from the one in Standard Dutch.

${ }^{5}$ A complication is that $e r$ can be omitted when the numeral is fronted and part of the surface subject. This is not necessarily a problem. er and the numeral cannot be fronted together, which shows that they do not form one constituent. When the subject numeral is fronted, er occurs in the subject position directly following the finite verb. This is a position in which other instances of er such as existential er can be omitted as well. Probably omission in this position is licensed by the finite verb which agrees with the subject.
} 
(3) Identification of [gender] in Standard Dutch noun ellipsis
a. (Over films gesproken)ik heb een leuk-e gezien
(about movies talked) I have a nice-NONNEUTER seen
Talking about movies, I have seen a nice one.
b. (Over boeken gesproken)\% ik heb een leukgelezen
(about books talked) I have a nice read
c. (Over die boeken gesproken), ik heb*(er) één gekocht
(about those books talked, I have (there) one bought
d. (Over films gesproken)ik heb (*er) één leuk-e gezien
(about movies talked) I have (there) one nice-NONNEUTER seen

According to the analysis sketched in this section, then, ONE insertion of the English type does not occur in Standard Dutch because Standard Dutch noun ellipsis requires the feature [gender] to be visible. This feature can be made visible by adjectival inflection or er, but not by één 'one' which neither has a [gender] feature nor can be inflected for [gender].

The precise nature of the empty nominal position and the way it is licensed is not my primary concern in this paper, but for the sake of concreteness I propose the following analysis. I assume that the empty nominal position is the result of noun deletion at PF which is subject to licensing conditions. ${ }^{6}$ Suppose [gender] is interpretable on nouns and uninterpretable on adjectives and determiners. Suppose further that [count] is interpretable on nouns and numerals, and uninterpretable (in the sense of Chomsky 1995) elsewhere. Suppose finally that a noun can be deleted at PF only if the deleted interpretable features are recoverable from a structurally adjacent head.

Consider now a Dutch DP in which the adjective is inflected for [gender]. This uninterpretable feature agrees with the interpretable [gender] feature on $\mathrm{N}$ and is thus checked. After checking, the feature is not passed on to LF, as this would cause the derivation to crash. The absence of the feature does not cause interpretive problems, because the noun itself is present at LF. At PF, however, the uninterpretable [gender] feature must be there, if we assume a late insertion model in which the feature is necessary to choose the right form of the adjective. The presence of the uninterpretable [gender] feature at PF makes N-deletion possible. Recoverability at PF is only relevant for the hearer. The presence of an uninterpretable [gender] feature in an input string based on this PF representation will be a signal for the hearer that the corresponding interpretable feature must have been present underlyingly. Similarly, the feature [count] will be recoverable in English by the local presence of a numeral or a determiner specified for [count]. If there is no local feature [count] available, PF deletion of the noun is impossible and will not occur. On this view, ONE-insertion in English happens when

\footnotetext{
${ }^{6}$ The analysis proposed here is partially compatible with the proposal in Panagiotidis (2003). Panagiotidis convincingly argues that the empty nominal position is not pro but an empty noun. He assumes that empty nouns are listed in the lexicon and not subject to licensing or identification requirements. However, his stipulation that English has a morphological requirement that Number must be spelled out is a licensing requirement in disguise, even though this licensing requirement can sometimes be overruled by pragmatic context. Importantly, the fact that features which play a role in licensing an empty nominal position must be local, as exemplified in (2), clearly demonstrates the morphosyntactic nature of empty noun licensing.
} 
the noun ONE is in the numeration instead of a lexical noun. ${ }^{7}$ ONE-insertion in English is not a last resort to save a structure with an illegitimately deleted noun. Theoretically, this is a desirable result, as ONE-insertion at PF would violate the Inclusiveness Condition (Chomsky 2001) which bars the introduction of new elements in the course of a derivation.

\section{Differences between English and the other ONE insertion varieties}

The next question is whether ONE insertion in the Northern-Brabantish and Groningen dialects and Frisian also serves to make the morphosyntactic feature [count] or some other feature locally visible. The answer to this question is negative. There are four differences. First, in English ONE cannot be deleted but in the other ONE insertion varieties it can (4). Secondly, English has ONE insertion and no adjectival inflection that could license an empty noun, the other ONE insertion varieties have both: ${ }^{8}$

$\begin{array}{rllll}\text { (4) a. Gè zet unnen } & \text { arig-en } & \text { (inne) } & \text { Northern Brabantish } \\ \text { you are a-MASC } & \text { strange-MASC-S } & \text { (one-MASC) } & \text { Frisian } \\ \text { b. } & \begin{array}{l}\text { Do bist eak in } \\ \text { rar-en }\end{array} & \begin{array}{l}\text { (ien) } \\ \text { you are also a }\end{array} \text { strange-SUFF } & \text { (one) } & \text { Groningen } \\ \text { c. } \begin{array}{l}\text { Doe bis ook 'n } \\ \text { you are also a }\end{array} & \text { strange-SUFF } & \text { (one) } & \end{array}$

Thirdly, only English allows ONE insertion in definite DPs:

(5) a. There are two men walking down the street.

English

I know the tall *(one).

$\begin{array}{lllll}\text { b. Diej-en } & \text { blond-en } \quad(\text { inne) } & \text { die ken } & \text { ik } & \text { Northern Brabantish } \\ \text { that-MASC } & \text { blond-MASC-S(one) } & \text { that know } & \text { I } & \end{array}$ I know the blond one.

c. de read-e (*ien)

the red-NON-NEUTER (one)

Frisian/Groningen

Fourthly, only English allows ONE insertion in plural DPs:

(6) a. Talking about rabbits:

there are two white *(ones) in the garden.

b. Er zitten twee witt-e (*een) in de tuin Frisian/Groningen

there sit two white-AGR one in the garden

c. Der zitte twee witt-e (*inne) in de tuin. Northern Brabantish

there sit two white-AGR one in the garden

\footnotetext{
${ }^{7}$ Cf. Panagiotidis (2003) for a similar view.

${ }^{8}$ The exact feature specification of the adjectival suffix in the Groningen and Frisian varieties is discussed below. Northern Brabantish makes a grammatical distinction between masculine, feminine and neuter, whereas Standard Dutch, Frisian and the Groningen dialects distinguish between neuter and non-neuter.
} 
The latter two differences raise the question as to why ONE insertion is possible in definite and plural DPs in English but not in the other ONE insertion varieties. I will answer this question by analyzing the morphosyntactic feature specification of ONE.

\section{ONE as an indefinite singular focus marker}

According to traditional grammar (e.g., Haeseryn et al. 1997) één 'one' in Standard Dutch belongs to the category of 'definite' numerals, numerals that refer to an exact number and differ in this respect from indefinite numerals such as veel 'many'. Closer examination reveals, however, that één 'one' is an indefinite numeral. ${ }^{9}$

A first difference between één 'one' and the 'definite' numerals is that één 'one' cannot serve as the basis for regular ordinal formation. An ordinal in Standard Dutch is derived by adding the suffix -de $(7 \mathrm{a}, \mathrm{b})$ or in some cases the superlative suffix -ste to the numeral (7c). With één 'one' we find suppletion (7d). The suppletive form eerste 'first' is the superlative of the temporal adjective eer 'early' (Buck 1949) or the preposition eer 'before' (WNT). This suppletion cannot be triggered by phonological conditions, in view of the fact that no suppletion occurs with tien 'ten', which has the same coda as één 'one'. ${ }^{10}$ één 'one' behaves parallel to veel 'many', which also has suppletion and does not allow regular ordinal formation (7e).

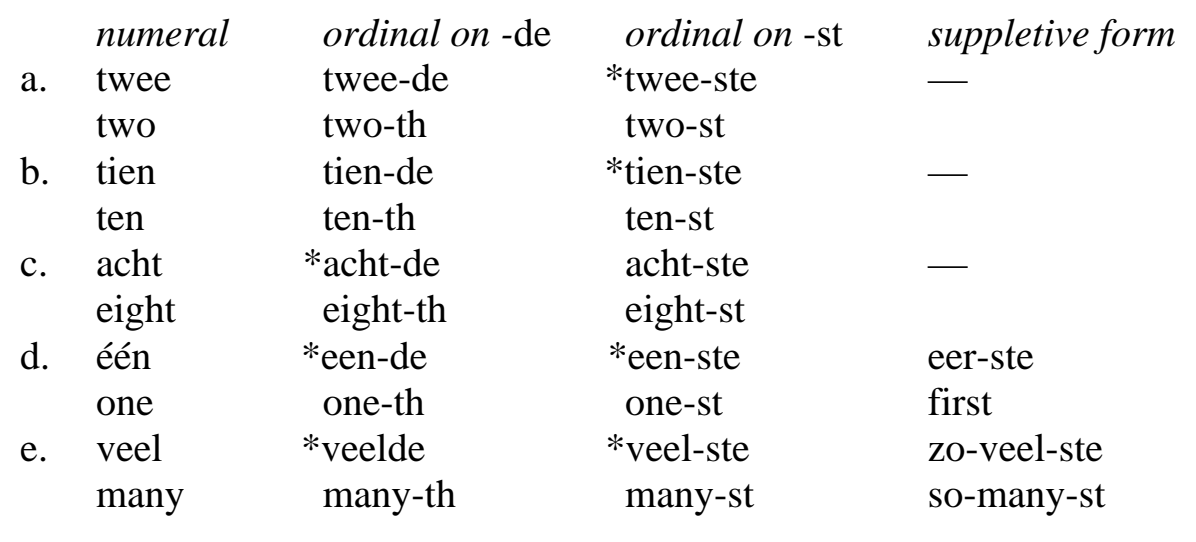

The obligatoriness of a suppletive form for the ordinal FIRST is not an accidental property of Standard Dutch. Veselinova (1996) shows that many languages have a suppletive form for FIRST. Some examples are given in (8).

\footnotetext{
${ }^{9}$ The traditional terminology is unfortunate in that DPs headed by a 'definite' numeral do not have the syntactic distribution of definite DPs. I will claim below that 'definite' numerals neither have a feature [definite] nor a feature [indefinite]

${ }^{10}$ French also shows neatly that a phonological explanation for this type of suppletion is inadequate. Whereas unième 'first' is ungrammatical, vingt-et-unième 'twenty-one' is $\mathrm{OK}$, and vingt-et-premier does not exist.
} 
(8)

$\begin{array}{lllr} & \text { numeral } & \text { ordinal } & \text { suppletive form } \\ \text { a. one } & \text { *one-th } & \text { first } & \text { English } \\ \text { b. un } & \text { *un-ième } & \text { premier } & \text { French } \\ \text { c. kelê } & \text { *kelê-na } & \text { folo } & \text { Maninka }^{11}\end{array}$

Veselinova provides a cognitive account for suppletion with FIRST. ${ }^{12}$ The attested suppletive forms often refer to the temporal or spatial domain. According to Veselinova the use of words from the temporal or spatial domain is cognitively the primary way to order a set linearly. Ordinals would only be a secondary way. However, the further differences between één 'one' and the other numerals described below do not follow from this explanation, whereas they do follow from the linguistic explanation proposed here.

A second difference between één 'one' and the 'definite' numerals is found with derivations on -heid '-ness'. één 'one' can be the input of such a derivation (9a), but the 'definite' numerals cannot. Instead, we find suppletive forms (9b-c). veel 'many' patterns with één 'one' (9d).

(9)
numeral
derivation
suppletive form
a. één
één-heid
one
one-ness
b. twee
$*_{\text {twee-heid }}{ }^{13}$
twee-eenheid, stel, paar, duo
two
two-ness
two-one-ness, couple, pair, duo
c. drie
*drie-heid
drie-eenheid, trits, trio
d. veel
three-ness
three-one-ness, trio, triplet
many
veel-heid
many-ness
'multitude'

A third difference concerns derivations with the suffix -tal 'number', 'some'. The definite numerals can be combined with this suffix (10a), but één 'one' and veel 'many' cannot $(10 \mathrm{~b}, \mathrm{c})$. *eental gives rise to suppletion.

\footnotetext{
${ }^{11}$ Maninka is a Niger-Congo language spoken in West Africa.

${ }^{12}$ Also for suppletion with SECOND, but Dutch and its varieties do not have suppletion there.

${ }^{13}$ We sometimes do find twee-heid 'two-ity' in philosophical and religious texts, often as a literal translation from Greek. This seems to be a constructed form that does not occur in written and spoken Dutch outside the domain of the philosophical and religious literature.
} 
(10) numeral derivation suppletive form
a. twee
twee-tal
two
two-some
b. één
*een-tal
c. veel one-some
enkel, enkeling
single
many
*veel-tal ${ }^{14}$
many-some

A fourth difference between één 'one' and the 'definite' numerals is that only één 'one' can be used predicatively (11a), just as veel 'many' (11b).
(11) a. Man
en vrouw
zijn één / *twee
man
and woman
are one / two
b. Veertig
deelnemers is
veel
participants is
many

A fifth difference is that één 'one' and veel 'many' must be inflected for definiteness when used attributively $(12 a, b)$, whereas 'definite' numerals cannot be inflected $(12 b) .{ }^{15}$
(12) a. het een*(-e) boek
the one-INFL book
b. de veel*(-e) boeken
the many-INFL books
c. de $\operatorname{tien}(*$-e) boeken
the ten-INFL books

Finally, whereas één 'one' and veel 'many' can be modified by zo 'so', definite numerals cannot $(13 \mathrm{a}, \mathrm{b})$. Modifyability by zo 'so' is a typical property of indefinites $(13 \mathrm{c}, \mathrm{d})$.
(13) a. zo één / veel
so one / many
b. *zo tien
so ten
'such a one, so many'
c. zo iemand / *hem
so someone / him
'someone like that'
d. zo iets / *het
so something / it
'something like that'

Table 1 provides an overview of the distributional parallels between één 'one' and veel 'many' and the differences with the 'definite' numerals.

\footnotetext{
${ }^{14}$ According to my own intuition and that of many other speakers veeltal 'multitude' is ungrammatical. It is not in the two major dictionaries of Dutch (WNT, Van Dale) and it does not occur in spoken language, as far as I know. Used as search word in Google (February 2003), veeltal gives 107 hits. In many cases this involves a literal translation of the English word tuple in texts from the ICT sector. The number of 107 hits is very low compared to, e.g. aan-tal 'some' (1,520,000 hits), vijf-tal 'five-some' (22,300 hits), twintig-tal 'twenty-some' (10.300 hits) and honderd-tal 'hundred-some' (6000) hits.

${ }^{15}$ The [definite] feature of the inflection on één 'one' and veel 'many' is not inherent, hence uninterpretable. Therefore, it does not cause a clash with the feature [indefinite] on één 'one' and veel 'many'. Cf. section 5 for a full account.
} 
Table 1: Distribution of indefinite and definite numerals

\begin{tabular}{|l|l|l|l|}
\hline & één 'one' & veel 'many' & tien 'ten' \\
\hline regular ordinal & $*_{\text {een-de }}$ & *veel-de & tien-de \\
\hline suppletive ordinal & eerste & zoveelste & - \\
\hline derivations with -heid & een-heid & veel-heid & *tien-heid \\
\hline derivations with -tal & *een-tal & *veel-tal & tien-tal \\
\hline predicative & yes & yes & no \\
\hline definiteness inflection & yes & yes & no \\
\hline modifyable by $\boldsymbol{z o}$ 'so' & yes & yes & no \\
\hline
\end{tabular}

It is tempting to conclude from this that één 'one' and veel 'many' are adjectives, since adjectives can also be used predicatively, they can be the input of derivations with -heid '-ness', they show definiteness inflection and they can be modified by zo 'so'. However, there are three strong arguments in favor of a numeral status: (i) één 'one' and veel 'many' can be the head of a partitive construction, like numerals and unlike adjectives (14a-d); (ii) With N-ellipsis, één 'one' and veel 'many' require the occurrence of quantitative $e r$ 'there', like numerals and unlike adjectives (14e,f); (iii) één 'one' and veel 'many' do not have (regular) comparative and superlative forms $(14 \mathrm{~g}, \mathrm{~h})$

(14) a. één van die boeken

one of those books

b. twee van die boeken

two of those books

c. veel van die boeken

many of those books

d. *rode van die bloemen $^{16}$

red of those flowers

e. Ik heb *(er) één / twee / veel

I have (there) one / two / many

f. Ik heb (*er) rode

I have (there) red

g. één - *één-er $\quad$ *één-st

one one-r one-st

$\begin{array}{rrr}\text { heel } & -*_{\text {veel-er }} \quad-\quad{ }^{*} \text { veel-st }{ }^{17} \\ \text { many } & \text { many-er } & \text { many-st }\end{array}$

\footnotetext{
${ }^{16}$ A reviewer suggests to use the adjective talrijk 'numerous' to demonstrate this point because (14d) could be out for semantic reasons. It is true that talrijke van die bloemen 'numerous of these books' is out for many speakers, thus supporting my claim, but unfortunately there are also speakers who accept it, in particular in the southern part of the Dutch language area. It is not so clear, however, why (14d) would be semantically unwellformed. A plausible interpretation of Ik stuur rode van die bloemen naar Marie lit. 'I send red ones of those flowers to Mary' could be 'Of those flowers I send some red ones to Mary'.

${ }^{17}$ Veel 'many' is traditionally associated with the irregular comparative and superlative meer 'more' and meest 'most'. As in the case of ordinal formation, I assume that obligatory suppletion shows that veel, like English many and French beaucoup, has an inherent, as yet unknown property that makes regular comparative and superlative formation impossible.
} 
On the basis of its morphological and syntactic distribution I conclude that één 'one' is an indefinite numeral, just like veel 'many'. The preliminary morphosyntactic feature specifications of één 'one' and veel 'many' and the 'definite' numerals are given in (15).
(15) Feature specifications of indefinite and 'definite' numerals (first version)
één 'one' [indefinite] [quantity: singular]
veel 'many' [indefinite] [quantity]
'definite' numerals [quantity: plural]

Although één 'one' and veel 'many' belong to the same category, they differ with respect to the underspecification of [quantity]. This is necessary for veel 'many' because it can occur both with count and mass nouns and with singular and plural (16a,b). As opposed to veel 'many', één 'one' forces a DP to be interpreted as countable (16c), and it is incompatible with a plural noun (16d).

(16) a. veel kaas (is beter dan weinig)

much cheese (is better than little)

b. veel kazen

many cheeses

c. één kaas (*is beter dan weinig)

one cheese (is better than little)

d. *één kazen

one cheeses

The 'definite' numerals differ from the indefinite ones primarily by the absence of the feature [indefinite] and secondarily by the specification [plural]. It is reasonable to assume that 'definite' numerals do not have a feature [definite], since bare numeral DPs can be the subject of existential clauses, unlike definite DPs (There are two / *the books on the table).

We are now in a position to answer the question of the previous section, why it is impossible to have ONE insertion in Northern Brabantish, Frisian and Groningen dialects with definite and plural DPs. Since één 'one' in these varieties behaves parallel to the Standard Dutch equivalent, it is reasonable to assume that it has the same feature specification. ONE insertion in a definite or plural DP in these language varieties would yield a structure in which ONE and the rest of the DP would not agree in definiteness and number.

To complete this section on the feature specification of één 'one', we look at the features [gender] and [focus]. Table 2 provides evidence for the presence of [gender] on ONE in Northern Brabantish exclusively. The table further shows that in all varieties discussed here ONE is the stressed form of the indefinite article. I take this as evidence that ONE has a feature [focus] in these varieties. 
Table 2: Evidence for the presence of [gender] and [focus]

\begin{tabular}{|c|c|c|}
\hline & indefinite article & één 'one' \\
\hline English & $\mathrm{a}$ & one \\
\hline $\begin{array}{l}\text { Frisian and } \\
\text { Groningen } \\
\text { dialects }\end{array}$ & in & ien \\
\hline $\begin{array}{l}\text { Northern } \\
\text { Brabantish } \\
\end{array}$ & $\begin{array}{l}\partial n \text {-FEM /NEUT } \\
\partial n n \partial-M A S C\end{array}$ & $\begin{array}{l}\text { één-FEM/NEUT } \\
\text { inne-MASC }\end{array}$ \\
\hline Standard Dutch & $\partial \mathrm{n}$ & één \\
\hline
\end{tabular}

This leads to the full feature specification given in (17). The specification for English involves the numeral ONE. In section 6.5 I will discuss inserted ONE in English, which only has the feature [count].

(17) Feature specification of the indefinite numeral ONE (final version) $)^{18}$

- English

- Standard Dutch

- Frisian \& Groningen dialects

- Northern Brabantish [indefinite] [singular] [focus]

[indefinite] [singular] [focus]

[indefinite] [singular] [focus]

[indefinite] [singular] [focus] [gender]

\section{Interlude: Explaining ordinal suppletion}

The impossibility of ordinal formation with één 'one' and veel 'many' can now be understood as a clash between the feature [indefinite] on ONE / MANY and the feature [definite] on the ordinal suffix. Hurford (1987) and Veselinova (1996) claim that ordinals are inherently definite as they select and point to a specific object from a context given ordered sequence of objects. This is supported by the fact that in languages such as Samoan and Turkana ordinal numbers are expressed by a combination of a cardinal with a definite article and a demonstrative, respectively. On the basis of these semantic and cross-linguistic considerations, I conclude that the homophony of the definite article de 'the' and the ordinal suffix -de '-th' in Dutch is not accidental and that we are dealing here with one and the same morpheme with an interpretable feature [definite]. More precisely, I would like to claim, slightly revising Hurford's and Veselinova's insight, that the ordinal suffix establishes a relation between a unique point on a linearly ordered sequence and the position of a person, in the unmarked case the deictic center of the speaker. This position is identified as the starting point (zero point) of the ordinally ordered set. This analysis of ordinals captures the fact that ordinality, unlike cardinality, depends on the point of view of a person; this person can be expressed by a experiencer PP (Dit is voor mij de derde keer 'This is the third time for me').

The clash between [indefinite] and [definite] only arises when both features are interpretable. This can be demonstrated with the constructions in (18)

$\begin{array}{lll}\text { (18) a. } & \text { en-e Jan } \\ & \text { one-DEF John } \\ & \text { a certain John }\end{array}$

\footnotetext{
${ }^{18}$ The specification [singular] is a simplification. Cf. (15).
} 
b. het en-e boek

the one-DEF book

In both cases, there is definiteness inflection on ONE. The reason why this does not cause a clash is that the [definite] feature of this inflection is uninterpretable. It is checked under agreement with the definite name and the determiner and hence deleted before it reaches LF. The presence of indefinite ONE in a definite DP in (18) gives rise to an interpretation which is definite and indefinite at the same time, thus supporting the claim that ONE inherently has a feature [indefinite].

\section{Syntactic analysis}

In this section we take up again the main issue of this paper, the analysis of ONEinsertion. We will see that the syntactic variation in ONE insertion constructions can be derived from the minimal difference in feature specification given in (17).

\subsection{Theoretical background}

It is a common assumption in the generative literature that in all languages DPs have the basic structure in (19), with at least the projections DP, NumP and NP. Articles occur in D, numerals in Num and nouns in N (cf. Bernstein 2001, Longobardi 2001 and references cited there). Adjectives are usually taken to be specifiers or adjuncts of NumP and NP. Surface word order variation is the result of head and/or XP movement within DP.

(19) $\left[{ }_{D P} D\right.$ the $\left[{ }_{\text {NumP }}\right.$ Num three $\left[{ }_{N P} \mathrm{~N}\right.$ books $\left.\left.]\right]\right]$

On the basis of cases like (20) I propose that the hierarchy NumP >> DP is also possible and in principle available in all languages (cf. Barbiers 1992).

$\begin{array}{rlll}\text { (20) a. } & \text { één zo } & \text { 'n } & \text { boek } \\ \text { b. } & \text { one such } & \text { a } & \text { book } \\ \text { c. } & \text { alle twee } & \text { de } & \text { boeken } \\ & \text { all two } & \text { the books }\end{array}$

The corresponding configuration is given in (21). 
(21)

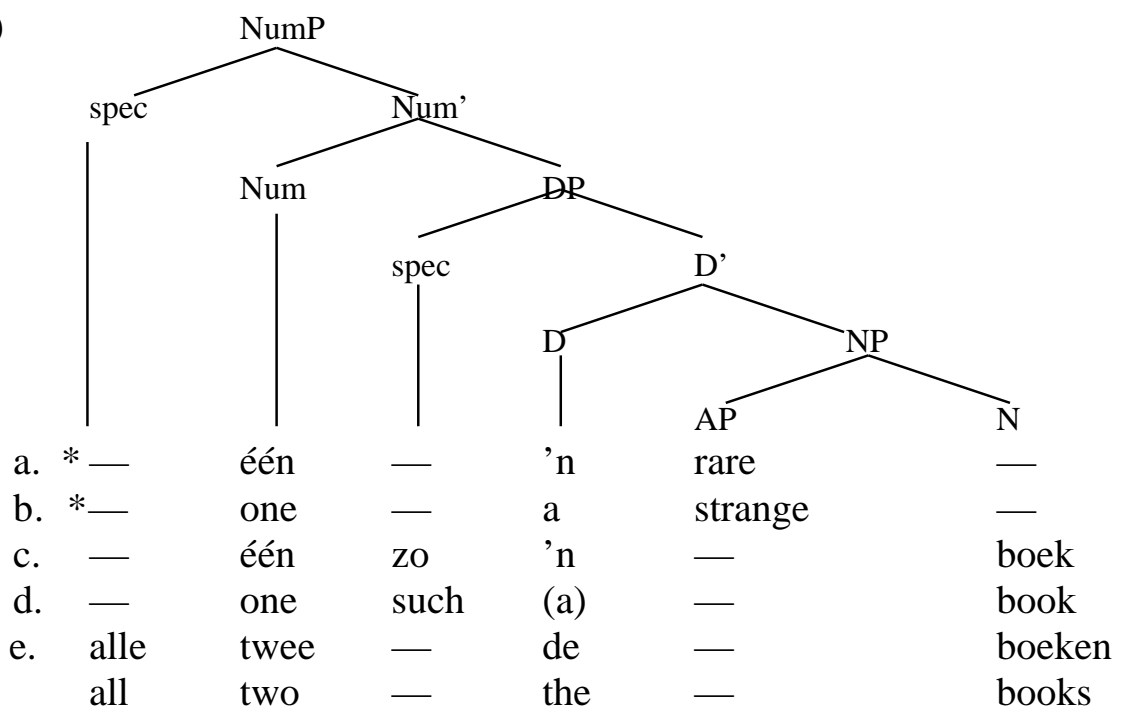

The assumption that the projection of the numeral dominates the projection of the determiner is unproblematic in the bare phrase structure framework (Chomsky 1995) according to which these labels are really shorthands for the features projected by the terminals of the nodes. In the case of één zo'n boek 'one such a book' the highest head één 'one' projects the features [indefinite], [singular], [focus]. Thus, all the features relevant for the external syntax of the nominal group are present on the highest projection (21), including the features of the indefinite article. The apparent unnaturalness of the hierarchy in (21) is just an artifact of the use of node labels.

The situation with alle twee de boeken 'lit. all two the books, both books' is slightly more complicated. The requirement that all features relevant for the external syntax of a nominal constituent should be visible on the highest maximal projection of such a constituent explains the minimal contrast in (22).
(22) a. *twee de boeken
two the books
b. alle twee de boeken
all two the books
both books

I have argued above that 'definite' numerals neither have a feature [definite] nor [indefinite]. As a result, the highest projection NumP in (22a) does not have a feature [definite], even though this feature is present in the nominal constituent and relevant for its external syntax. If we assume that in (22b) alle 'all' is in SpecNumP and has a feature [definite] that percolates up to NumP (via head spec agreement), the NumP in (22a) has all the features relevant to the external syntax of alle twee de boeken. ${ }^{19}$

Let us now consider (21) more closely. A first question is why *één ' $n$ rare (21a) and

\footnotetext{
${ }^{19}$ Alternatively, alle 'all' could be generated in the highest head position of the nominal constituent. This would not have consequences for the analysis, since alle plausibly has a plural feature too, such that in this case too all features would be visible on the highest projection.
} 
*one a strange (21b) are ungrammatical, while *één zo'n boek (21c) and one such a book (21d) are not. In (21a) één and ' $n$ are adjacent. één has the features [indefinite] [singular] [focus], while ' $n$ has the features [indefinite] [singular]. The same situation obtains in English. The ungrammaticality of (21a) and (21b) can be understood as a violation of a requirement to leave a position empty under adjacency of redundant features. ${ }^{20}$ When there is no adjacency, as in $(21 \mathrm{c}, \mathrm{d})$ where $z o$ and such intervene between the numeral and the article, the article must be spelled out in Dutch and can be spelled out in English. The proposed haplology rule is given in (23). Although the rule refers to D and Num, it is plausible that it is applicable to other syntactic categories as well.

\section{(23) Haplology rule}

Leave D empty at PF when D and Num are adjacent and the features of D are a subset of the features of Num.

The structure in (21) will enable us to account for the properties of ONE insertion in Northern Brabantish and the lack of ONE insertion in Standard Dutch.

\subsection{Northern Brabantish}

I would like to claim that ONE insertion in Northern Brabantish arises when DP moves to SpecNumP in (21). The result is given in $(24){ }^{21}$

(24) ONE insertion in Northern Brabantish

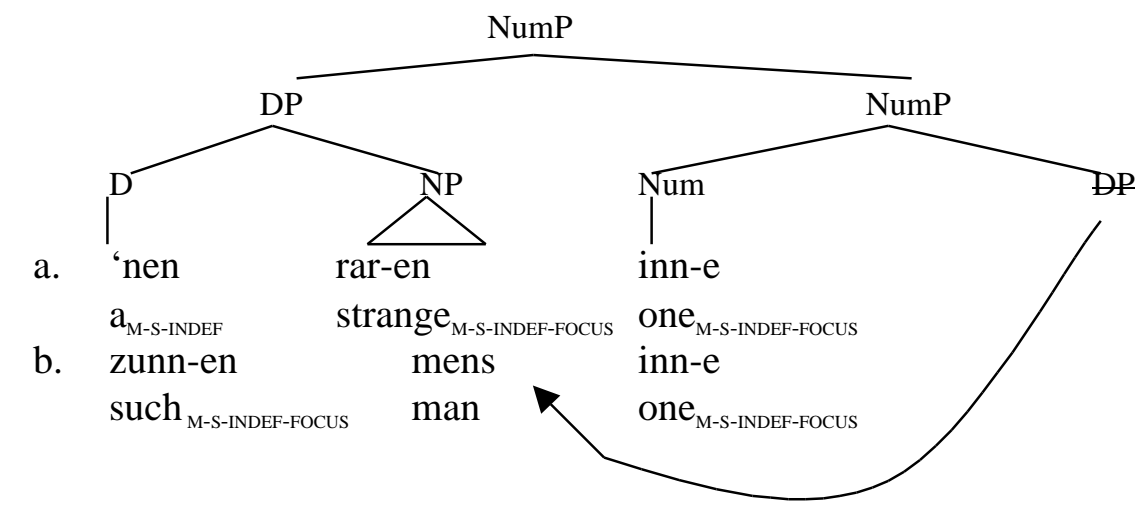

Focus is the trigger of this movement operation, as in many other constructions that involve displacement. The adjective or AP in a noun ellipsis construction has focal stress obligatorily. The [focus] feature of this AP percolates to DP and matches with the [focus] feature on inne 'one'. This makes it possible for the entire DP to move to SpecNumP. ${ }^{22}$

\footnotetext{
${ }^{20}$ Cf. Szabolcsi (1994) for a similar haplology rule for nominal constituents in Hungarian. Cf. Neeleman \& van der Koot (2003) for a general discussion of syntactic haplology.

${ }^{21}$ Cf. Kayne (1994) for IP to SpecCP movement.

${ }^{22}$ The question as to whether this movement is mediated by an EPP feature (Chomsky 2000, 2001) is irrelevant for present purposes, as is the question which of the two [focus] features is unvalued/uninterpretable.
} 
I assume that the operation in (24) must satisfy the requirement in (25), which can be seen as a special case of the assumption in Chomsky $(2000,2001)$ that movement is only possible to the edge of complete constituents, where complete means (among other things): having a complete set of $\varphi$-features.

\section{(25) Condition on movement of XP to SpecYP}

Movement of XP to SpecYP is possible iff there is full agreement between $\mathrm{XP}$ and $\mathrm{Y}$.

In Northern Brabantish there is full agreement between DP and Num. Num inne 'one' has the features [indefinite], [singular], [gender] and [focus]. DP has the features [indefinite], [singular] and [gender] by virtue of the percolation of the features of the terminal of $D$, 'nen, and it inherits a [focus] feature of the AP that it contains. Definite and plural DPs do not occur in this construction since their features clash with the features of Num inne 'one' (cf. examples (5) and (6)).

This analysis leads to the expectation that noun ellipsis is not a necessary condition for ONE insertion in Northern Brabantish, as long as DP agrees fully with Num. This expectation is correct. In (26a), there is a [focus] feature on zo'n 'such a' and in (26b) on duigeniet 'knave'. All attested examples have [focus] with a corresponding high degree interpretation (cf. also the examples in (27)).

(26) a. [Zo'n mins een]hi altet wè um over te klage N. Brabantish [such-a person one]has always what for about to complain Such a man has always something to complain about.

$\begin{array}{lllll}\text { b. } & t \text { Is }[\text { enen } & \text { duigeniet } & \text { eene }] & \text { N. Brabantish } \\ \text { it is }[\mathrm{a} & \text { knave } & \text { one }] & \end{array}$ He really is a knave!

Another observation supporting the correctness of the structure in (24) is that DP, being a constituent at the left edge of NumP, can extract from NumP. ${ }^{23}$

(27) a. [ DPP $\mathrm{E}$ völ kiendje $]$ bende $\left[_{\mathrm{NumP}}\left[_{\mathrm{DP}} \mathrm{e}\right.\right.$ völ kiendje $]$ een]!
a dirty kid

You're a very dirty kid!

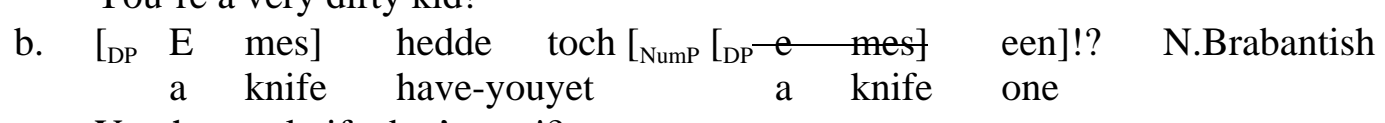
You have a knife don't you!?

c. [DP 'nen aorige $]$ ben-de wel $\left[_{\mathrm{NumP}}\left[{ }_{\mathrm{DP}}\right.\right.$ 'nen aorige $]$ inne] N. Brabantish a strange are-you really a strange one You really are a strange one!

The remaining property of Northern Brabantish ONE insertion that must be explained is its optionality. I assume that ONE insertion is optional because DP to SpecNumP

\footnotetext{
${ }^{23}$ The examples in (26b) and (27a,b) are from de Bont (1962).
} 
movement is optional, like many other movement operations triggered by focus. When DP does not move to SpecNumP, the numeral and the article will end up in adjacent positions and the haplology rule in (23) will apply. As a result, the article will not be visible. $^{24}$

\subsection{Standard Dutch}

In Standard Dutch, ONE insertion is only visible in the construction in (21c), één zo 'n boek lit. 'one such a book'. één 'one' does not appear at the end of a nominal constituent, because the full agreement condition in (25) is not satisfied. The reason is that één 'one' in Standard Dutch does not have a [gender] feature. DP in Standard Dutch, however, always has a [gender] feature, which is introduced by $\mathrm{N}$ and which may also be visible on $\mathrm{D}$ or A. As we have seen in section 2, [gender] must be visible in noun ellipsis. As a consequence of this asymmetry in the presence of [gender], there cannot be full agreement between Num één 'one' and DP, and DP movement to SpecNumP is impossible.

A conceivable alternative explanation for the difference between Northern Brabantish and Standard Dutch would be that DP movement to SpecNumP is obligatory and overt in both varieties, but that they differ with respect to PF deletion of éen 'one': obligatory in Standard Dutch, optional in Northern Brabantish. However, such an explanation wrongly predicts that (21c), één zo 'n boek lit. 'one such a book' should be ungrammatical. After moving [zo'n boek] to the left of één, één should delete, and the result would be zo'n boek instead of één zo'n boek.

\subsection{Frisian and Groningen dialects}

In Frisian and the Groningen dialects we find the same asymmetry in the distribution of [gender] as in Standard Dutch. [gender] is never present on ONE and always present on DP, hence there will never be full agreement between Num and DP. Therefore, DP to SpecNumP cannot be the right analysis of ONE insertion in Frisian and the Groningen dialects. This conclusion is supported by the observation that ONE insertion without noun ellipsis (as in (26)) and DP extraction from NumP (as in (27)) are impossible in Frisian and the Groningen dialects, as (28) shows.

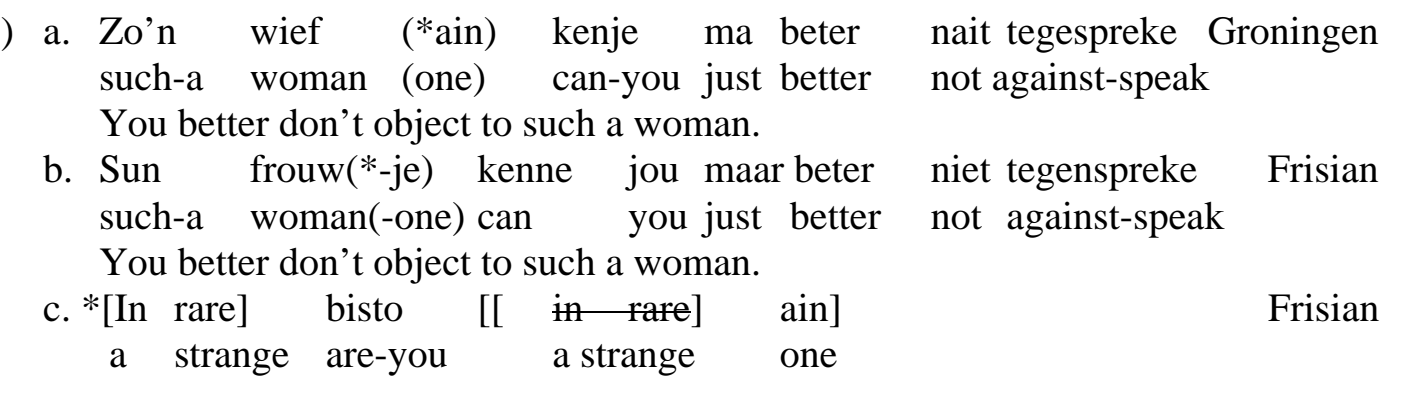

\footnotetext{
${ }^{24}$ For indefinite singular DPs without the numeral ONE, there are various options: (i) Num is not present, (ii) The indefinite article is generated under Num and moves to D, (iii) An indefinite article is generated under both D and Num, and one of them deletes as a result of haplology. I will not attempt to choose between these options.
} 
For Frisian and the Groningen dialects I propose that ONE insertion is the result of AP movement to SpecNumP in a structure with the hierarchy DP $>$ NumP $>$ NP, the 'unmarked' hierarchy that is available in all varieties under discussion, just like the hierarchy NumP >> DP >> NP.

(29) ONE insertion in Frisian and Groningen dialects

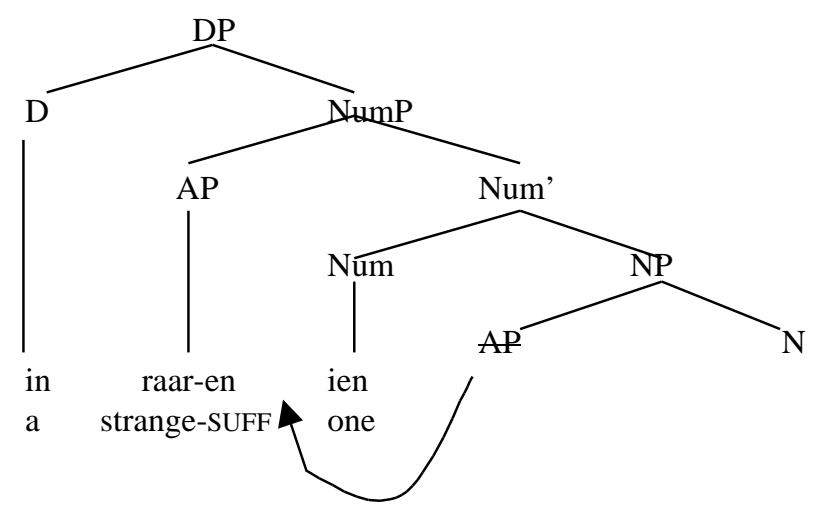

In this construction in raren is not a constituent, which explains why splitting in raren from ien as in (28c) is impossible in Frisian and the Groningen dialects.

At first sight, AP movement to SpecNumP seems to violate the full agreement condition in (25). Adjectives in Frisian and the Groningen dialects normally show [gender] inflection, but ien 'one' has no [gender] feature. Interestingly, in the noun ellipsis construction in these varieties, there is no [gender] inflection on the adjective. Instead, the suffix -en occurs which does not vary with the gender of the noun. This is illustrated for Frisian in (30).
a. in moai
a nice
boek
[neut][indef][sing]
Frisian
book
b. in saai-en
(ien)
(one)
c. in donker-e
a dark-NON-NEUTER
jongen
[neut][indef][sing]
Frisian
boy
e. in donker-en
(ien)
a dark-SUFF
(one)
[non-neut][indef][sing] Frisian
[non-neut][indef][sing] Frisian

This genderless suffix may also occur on the adjective when $\mathrm{N}$ is overtly present, but only in indefinite singular DPs. In such cases, it expresses focus or high degree (Tiersma 1995).
(31) a. Hy is in dreg-en baas he is a tough-FOC boss He is a very tough boss.
b. It is in djipp-en tinker it is a deep-FOcthinker
'He is a very deep thinker.'
Frisian
Frisian


I conclude that AP movement to SpecNumP is possible in Frisian and Groningen dialects precisely because these varieties have a suffix with the features [indefinite] [singular] [focus] but without [gender]. This suffix and hence the entire AP is in full agreement with ONE, so (25) is satisfied. This analysis also explains why noun ellipsis is a necessary condition for ONE insertion in these varieties but not in Northern Brabantish. ONE insertion with an overt noun requires NP movement to SpecNumP in (29), hence full agreement between NP and Num. However, NP has a [gender] feature and ONE does not, so full agreement does not arise.

The Frisian/Groningen variant of ONE insertion is absent in Standard Dutch because Standard Dutch does not have a genderless focus suffix that makes full agreement between AP and Num possible. Therefore, ONE insertion as the result of AP to SpecNumP movement does not occur in Standard Dutch $(32 \mathrm{a}, \mathrm{b})$. This is different in the plural. In the plural, adjectives in Standard Dutch only show inflection for [plural], not for [gender]. 'Definite' numerals also only have a feature [plural] (cf. section 4). They have no [gender] inflection and differ from één 'one' in that they lack the feature [indefinite]. Consequently, under the assumption that APs and definite numerals can optionally have a [focus] feature, there is full agreement between adjectives with plural inflection and 'definite' numerals such as twee 'two'. This makes AP movement to SpecNumP possible (32c,d).

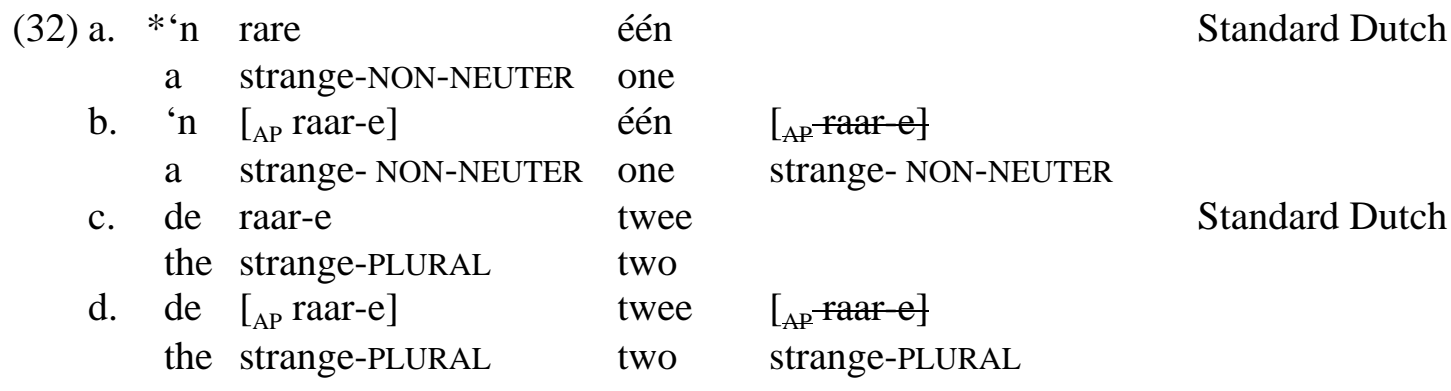

\subsection{English}

In section 2 it was shown that English one in the ONE insertion construction may occur in definite and plural DPs and represents the feature [count] in such cases. Without noun ellipsis one cannot occur in plural or definite DPs (33a-c). We must conclude that English has two different one's, an indefinite numeral with the features [indefinite], [singular], [focus] that occurs in Num and a pronoun with the feature [count] that occurs in N. ${ }^{25}$ The two types of one may cooccur, as (33d) shows.

(33) a. one such a red book

$\left[_{\mathrm{NumP}}\right.$ one $\left[_{\mathrm{DP}}\right.$ such a $\left[_{\mathrm{NP}}\right.$ red $[$ book] $\left.\left.]\right]\right]$

b. *one the red book

$\left[_{\mathrm{NumP}}\right.$ one $\left[\mathrm{DP}\right.$ the $\left[\mathrm{NP}_{\mathrm{NP}}\right.$ red [book]]]]

c. *one red books

$$
\left[\mathrm{DP}\left[\mathrm{NumP} \text { one }\left[{ }_{\mathrm{NP}} \text { red }[\text { books }]\right]\right]\right]
$$
${ }^{25}$ This is the traditional analysis for English; e.g., Longman's dictionary (1987) distinguishes between
determiner one and pronoun one. 
d. one red one

$\left[_{\mathrm{DP}}\left[_{\mathrm{NumP}}\right.\right.$ one $\left[_{\mathrm{NP}}\right.$ red [one $\left.\left.\left.]\right]\right]\right]$

If we assume that English nouns always have a feature [count] or [mass] (cf. section 2), then there will never be full agreement between the numeral one and the DP. ${ }^{26}$

Consequently, the Northern-Brabantish type of one insertion is impossible in English: there is no one insertion when the noun is overt (34a) and Num and DP cannot be split (34b).

(34) a. *He is a strange man one

b. $\quad *\left[_{D P}\right.$ A strange $]$ is he $\left[{ }_{\mathrm{NumP}}\left[{ }_{\mathrm{DP}}\right.\right.$ a strange $]$ one $]$

Since adjectives in English are completely featureless and there is no special suffix in noun ellipsis contexts, the Frisian/Groningen variant of one insertion is absent from English as well.

\section{Conclusion}

At first sight, ONE insertion is a heterogeneous phenomenon. In Northern Brabantish it is the result of optional DP movement to SpecNumP. In Frisian and some Groningen dialects it is the result of AP movement to SpecNumP. In English ONE is generated in the position of N. Standard Dutch does not show ONE insertion, if we restrict the term ONE insertion for cases in which ONE is in the right periphery of the nominal group. However, it was shown that if we take it to include cases in which ONE is in the left periphery of the nominal group, more specifically to the left of the indefinite article, then even Standard Dutch has ONE insertion.

The differences between the language varieties discussed in this paper neither reside in variation in the possiblity for ONE to cooccur with an indefinite article, nor in variation of the base structures available. The available base structures are the same: DP > NumP >> NP and NumP >> DP >> NP. It was argued that variation in ONE insertion can be derived from the interaction between the morphosyntactic feature specification of the various elements in the nominal group and the condition that movement to SpecNumP is only possible when there is full agreement between ONE in Num and the constituent that moves to SpecNumP.

In Northern Brabantish full agreement between DP and ONE obtains because ONE has a [gender] feature, a feature that is lacking on ONE in Standard Dutch, Frisian and the Groningen dialects. In Frisian and the Groningen dialects exceptional full agreement arises by virtue of a special adjectival suffix that neutralizes the gender distinction and provides the features [indefinite], [singular], [focus] that are necessary for full agreement with ONE. In English, adjectives are featureless and nouns have a feature [count] or

\footnotetext{
${ }^{26}$ Although the logic of this explanation is sound, it is not completely satisfactory in view of the question whether it is possible to distinguish the feature [count] of $\mathrm{N}$ from the feature [singular] of one. An alternative possibility is that English nouns are featureless and therefore cannot agree with one. Since it is the syntactic context that determines whether a certain noun must be interpreted as count noun or mass noun, the assumption that the [count] feature is not inherent to nouns is attractive. If nouns are featureless in English, however, this raises the question why the feature [count] must be visible in noun ellipsis. I leave this issue for future research.
} 
[mass] that is lacking on ONE. Therefore, full agreement and ONE insertion of the Northern Brabantish or Frisian type does not arise in English.

The feature [indefinite] on ONE is crucial for the possibility to have full agreement with a DP that contains an indefinite article. Independent evidence for the novel claim that numeral ONE has a feature [indefinite] comes from four morphological contexts in which Dutch één 'one' patterns with the indefinite numeral veel 'many' rather than with the definite numerals twee 'two', drie 'three' etc.

English has its own type of ONE insertion, because it has a noun ONE in addition to the numeral ONE. As opposed to numeral ONE, noun ONE does not have the features [indefinite] and [singular]. Therefore, it can occur in plural and definite DPs. The other language varieties that we discussed do not have a noun ONE.

ONE insertion in Northern Brabantish and Frisian and Groningen dialects is a way to focus a part of the nominal constituent, but it is not necessary for licensing noun ellipsis, as adjectival inflection can do that job. In English, ONE insertion is necessary to license noun ellipsis by the visibility of the feature [count]. As a result of ONE insertion in English, the adjective or AP is in focus. Thus, although the syntactic structure of ONE insertion in English differs from the other language varieties, the effect in terms of information structure is the same. Noun ellipsis in Standard Dutch requires visibility of the feature [gender]. In Frisian and the Groningen dialects, it requires the visibility of the features [indefinite] and [singular]. In Northern-Brabantish the situation is less clear.

We have thus identified the following sources of cross-linguistic variation:

(i) Varying morphosyntactic feature specification of D, Num, A, N;

(ii) Availability of a noun ONE.

(iii) Availability of a special gender neutral suffix to license noun ellipsis.

(iv) Full or partial agreement between Num and DP/AP, and consequently, movement or no movement of DP/AP to SpecNumP.

Since (iv) is an automatic consequence of the variables (i) - (iii), which all involve variation of morphosyntactic feature specifications in the lexicon, the cross-linguistic syntactic variation in ONE insertion derives entirely from the lexicon. The results of the research reported in this paper therefore strongly support the central hypothesis of the Minimalist Program that all variation is in the lexicon, not in in the syntactic component of the grammar.

\section{Bibliography}

Barbiers, Sjef: 1990, ‘Telwoorden, adjectiven en lege NPs', unpublished master thesis, Leiden University.

Barbiers, Sjef: 1992, 'Adjectives as auxiliaries of the noun phrase', in R. Bok-Bennema and

R. van Hout (eds.), Linguistics in the Netherlands 1992. John Benjamins,

Amsterdam/Philadelphia, pp. 13-24.

Bernstein, Judy: 2001, 'The DP Hypothesis', in M. Baltin and C. Collins (eds.)

The Handbook of Contemporary Syntactic Theory. Blackwell, Malden, pp. 536-561.

Bont, A.P. de 1962. Dialekt van Kempenland, meer in het bijzonder d'Oerse taol. Deel I, van Gorcum, Assen.

Buck, Carl Darling: 1949, A Dictionary of Selected Synonyms in the Principal Indo-European Languages. The University of Chicago Press.

Chomsky, Noam: 1995, The Minimalist Program, MIT Press, Cambridge. 
Chomsky, Noam: 2000, 'Minimalist Inquiries: The framework', in R. Martin et al (eds.), Step

by step: Essays on Minimalist syntax in honor of Howard Lasnik:, MIT Press, Cambridge.

Chomsky, Noam: 2001, 'Derivation by Phase', in M. Kenstowicz (ed.), Ken Hale, A life in Language, MIT Press, Cambridge.

Haeseryn, Walter, et al. (eds.): 1997, Algemene Nederlandse Spraakkunst, Martinus Nijhoff, Groningen, Wolters Plantyn, Deurne.

Hoekstra, Jarich: 1997, 'Absolutely intensifying adjectives and the emphatic marker -e in North Frisian (Fering-Öömrang), West Frisian and other West Germanic languages', in: G. de Haan, \& O. Vries (red.), Dedicated to Bo Sjölin (= Us Wurk 46), pp. 90-117.

Hurford, James: 1987, Language and Number. The Emergence of a Cognitive System, Blackwell, Oxford.

Kester, Ellen-Petra: 1996, The Nature of Adjectival Inflection, OTS, Utrecht.

Longman, 1987: Longman Dictionary of Contemporary English, Longman Group, Harlow

Longobardi, Giuseppe: 2001, 'The structure of DPs: Some Principles, Parameters and Problems', in M.

Baltin and C. Collins (eds.), The Handbook of Contemporary Syntactic Theory, Blackwell, Malden, pp. 562-603.

Panagiotidis, Phoevos: 2003, 'Empty nouns', Natural Language and Linguistic Theory 21 (2), pp. 381-432.

Szabolcsi, Anna: 1994, 'The noun phrase', in F. Kiefer en E. Kiss (ed.), The Syntactic

Structure of Hungarian, Syntax and Semantics 27, Acadmic Press, San Diego.

Tiersma, Pieter Meijes: 1985, Frisian Reference Grammar, Foris Publications, Dordrecht.

Veselinova, Ljuba: 1996, 'Suppletion in the derivation of ordinal numerals: a case study', in MIT Working Papers in Linguistics 26.

WNT, Woordenboek der Nederlandsche Taal. The Hague: SDU Uitgeverij. 